\title{
Gold(I)-catalyzed enantioselective synthesis of tetrahydrocarbazoles through dearomative [4+2] cycloadditions of 3/2-substituted 2/3-vinylindoles
}

\author{
Valentina Pirovano, ${ }^{\mathrm{a}^{*}}$ Micol Borri, ${ }^{\mathrm{a}}$ Giorgio Abbiati, ${ }^{\mathrm{a}}$ \\ Silvia Rizzato ${ }^{\mathrm{b}}$ and Elisabetta Rossi ${ }^{*}$
}

\begin{abstract}
a Dipartimento di Scienze Farmaceutiche, Sezione di Chimica Generale e Organica “'A. Marchesini”, Università degli Studi di Milano, Via Venezian 21, 20133 Milano, Italy.

Tel. +390250314474, Fax +390250314476, e-mail: valentina.pirovano@unimi.it or elisabetta.rossi@unimi.it.

${ }^{\mathrm{b}}$ Dipartimento di Chimica, Università degli Studi di Milano, Via Golgi 19, 20133 Milano, Italy.
\end{abstract}

\begin{abstract}
The gold-catalyzed synthesis of tetrahydrocarbazoles through dearomative [4+2] cycloaddition reactions of 3/2substituted 2/3-vinylindoles with allenamides is reported. In particular, we optimized the enantioselective variant of these cycloadditions. Using allenamides as dienophiles 3-substituted-2-vinyl indoles gave the corresponding carbazoles with high chemo-, regio- and enantioselectivity. Good results were obtained also with 2-methyl-3-vinylindoles even if mixture of ( $Z$ ) and $(E)$ isomers were isolated in high $e . r$. and in excellent overall yields.
\end{abstract}

Keywords: vinylindole; allenamide; [4+2] cycloadditions; gold; asymmetric catalysis

\section{Introduction}

Carbazole and tetrahydrocarbazole rings are the key structural motif in a huge number of biological active molecules, including natural alkaloids and synthetic products. ${ }^{[1]}$ For this reason, strategic syntheses of these indole derivatives are highly required, in particular when based on asymmetric methodologies. In this research field, 2- and 3-vinylindoles have become versatile four-carbon building blocks for the synthesis of complex tetrahydrocarbazole derivatives by means of [4+2] cycloaddition reactions with activated dienophiles. ${ }^{[2]}$ Over the last years, the use of these heterocyclic dienes in Lewis acid ${ }^{[3]}$ or organocatalyzed $[4+2]$ cycloadditions $^{[4]}$ increased rapidly. However, application of these methodologies in enantioselective transformations is still limited and based mostly on organocatalytic methods. Thus, organocatalytic methodologies applied to enantioselective [4+2] cycloaddition reactions work either in the presence of hydrogen bond donor ${ }^{[5]}$ or chiral phopsphoric acid ${ }^{[6]}$ catalysts or through the generation of iminium ions ${ }^{[7]}$ from enones and properly substituted secondary amines (Scheme 1).

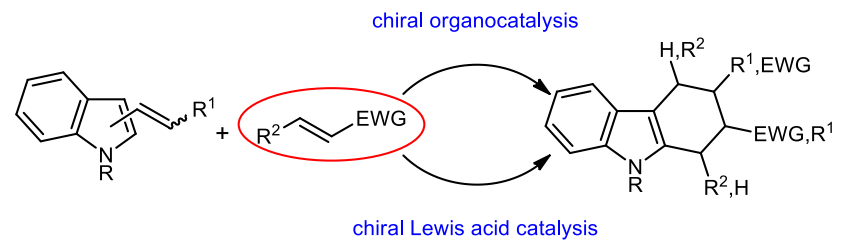

2- or 3-vinylindoles + classical dienophile enantioenriched carbazole derivatives
On the contrary, examples of asymmetric Lewis acid catalyzed [4+2] cycloadditions of 2- and 3vinylindoles are quite rare and only recently some groups reported the development of chiral Lewis acid as active catalysts in these transformations (Scheme 1). ${ }^{[8]}$

Recently, it has been shown that gold activated allenes participate in a great number of intermolecular annulation reactions, including $[4+2]$ processes. ${ }^{[9]}$ Pionering work by Wang, Goek ${ }^{[9 \mathrm{~m}]}$ and Mascareñas ${ }^{[9 n]}$ demonstrated that simple allenyl ethers and allenamides are efficiently activated towards the cycloadditions with dienes by gold(I) catalysts. In particular, reactions catalyzed by cationic gold triphenylphosphane or heterocyclic carbene complexes as well as by simple $\mathrm{AuCl}$ lead regioselectively to the corresponding cyclohexene derivatives. In both these works, the proposed reaction mechanism involves gold coordination at the terminal double bond of the allene followed by the formation of a gold-stabilized allylcation able to participate in the $[4+2]$ cycloaddition reaction. Furthermore, Mascareñas and co-workers described the enantioselective version of these cycloadditions, performed with a new class of $\mathrm{C}-2$ ligands featuring a triazole unit embedded to rigid cyclic framework. ${ }^{[0]}$ The reported reaction represents the first asymmetric intermolecular [4+2] cycloaddition promoted by a chiral carbophilic metal complex. According to the same heading, several papers dealing with [4+2] cycloadditions of 2- and 3-vinylindoles with allenes as dienophiles and occurring under gold-activation appeared in the literature (Scheme 2). ${ }^{[10]}$

Scheme 1. Enantioselective [4+2] cycloadditions of vinylindoles with classical dienophiles. 
a)

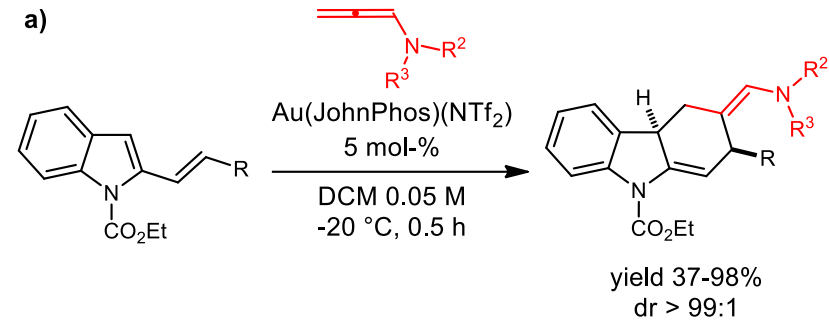

b) OPiv gold-catalyzed

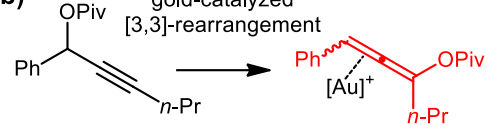<smiles>CCOn1c(/C=C/[P])cc2ccccc21</smiles>

$\mathrm{Au}\left(L^{*}\right) \mathrm{Cl} 5 \mathrm{~mol}-\%$ $\mathrm{AgNTf}_{2} 4.5 \mathrm{~mol}-\%$
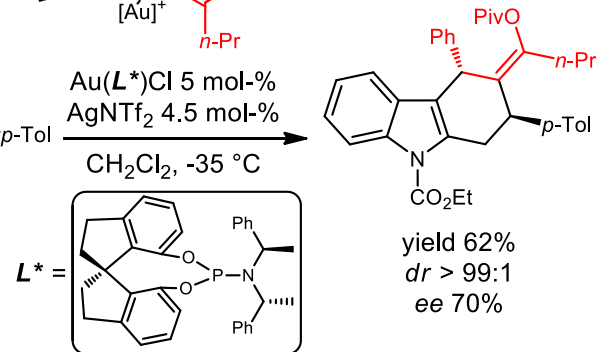

yield $62 \%$

$d r>99: 1$ ee $70 \%$

c)

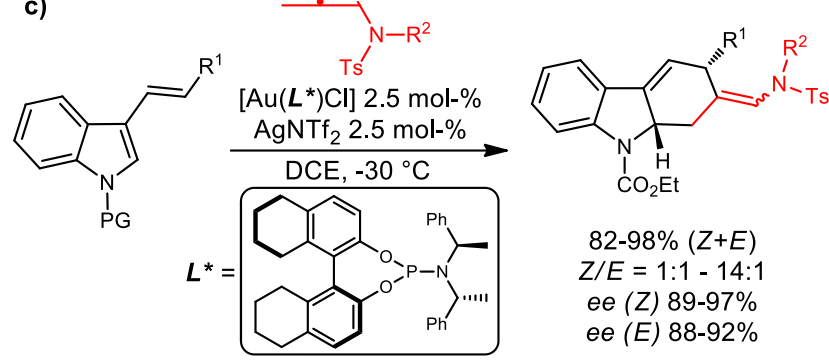

Scheme 2. [4+2] cycloadditions of vinylindoles with allenes under gold-activation.

In particular, we published the first example of gold catalyzed reaction of 2- and 3-vinylindoles with allenamides ${ }^{[10 a]}$ (Scheme 2a) and allenyl esters (Scheme 2b). ${ }^{[10 \mathrm{c}]}$ In this latter work we reported also some preliminary investigations on enantioselective synthesis of tetrahydrocarbazoles, reacting 2vinylindoles and allenyl esters in the presence of a chiral gold(I) phosphoramidite catalyst. Therefore, under our best reaction conditions, we observed the formation of the desired product in good yield and with an encouraging e.e. of $70 \%$. Moreover, related enantioselective reactions performed with 3vinylindoles and allenamides were reported by Xia and Zhang (Scheme 2c). ${ }^{[10 b]}$ In particular, they studied the reactions of 3-vinylindoles with $N$-allenamides catalyzed by chiral $\mathrm{H}_{8}$-BINOL-derived phosphoramidite gold(I) complex. However, both $(E)$ and $(Z)$-isomers at the exocyclic double bond were isolated in variable ratios and each of them in good to excellent enantiomeric excesses.

Prompted by these results and taking into account the importance of asymmetric tetrahydrocarbazole synthesis, we decided to explore the reactivity of 3/2substituted-2/3-vinylindoles with $\mathrm{N}$-allenamides under chiral gold(I) catalysis for the synthesis of a new series of dearomatized indoles bearing a quaternary $\mathrm{C} 4 \mathrm{a} / \mathrm{C} 9 \mathrm{a}$ stereocenter. Herein, we report the complete survey of the obtained results.

\section{Results and Discussion}

We started our investigations using 3-methyl-2vinylindole $\mathbf{1 a}$ and $N$-allenamide $\mathbf{2 a}$ in a model reaction in order to evaluate the activity of various gold species. The obtained results are summarized in Table 1.

Table 1. Screening of reaction conditions for the synthesis of $3 \mathbf{a}^{[\mathrm{a}]}$

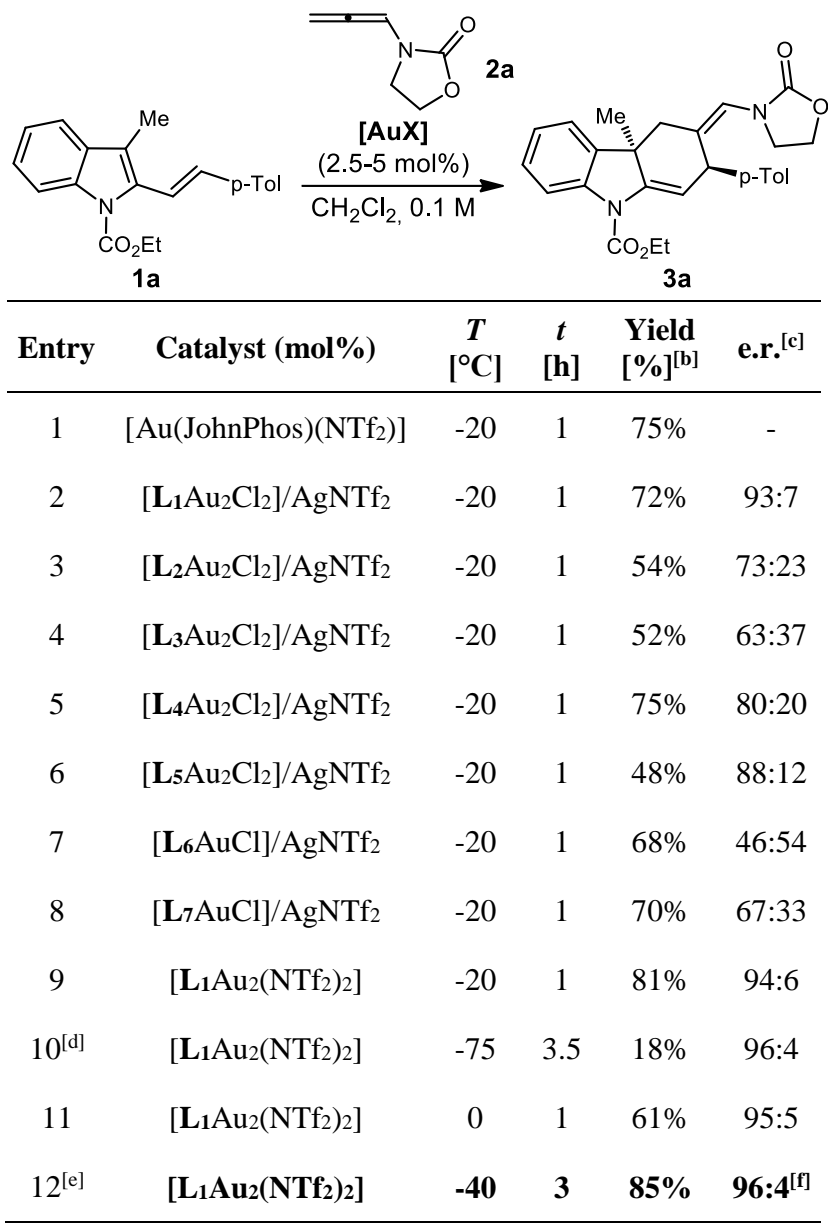

[a] Reaction conditions: 1a $(0.2 \mathrm{mmol}), \mathrm{N}$-allenammide $\mathbf{2 a}(0.9$ equiv.), gold(I) catalyst, [Au(JohnPhos)( $\left.\left.\mathrm{NTf}_{2}\right)\right]$ (5 mol\%); L1-L5 (2.5 mol\%); $\mathbf{L}_{6}-\mathbf{L}_{7}$ (5 mol\%), AgNTf 2 , when used, (5 mol\%), in $\mathrm{CH}_{2} \mathrm{Cl}_{2}(0.1 \mathrm{M})$. [b] Isolated yield. [c] Determined by HPLC on pure isolated product. [d] Unreacted 1a was recovered (>70\%). [e] Performed with 1.2 equiv. of allenamide 2a. [f] Increased to 99:1 after one single recrystallization. JohnPhos $=(2-B i p h e n y l)$ di-tertbutylphosphine.

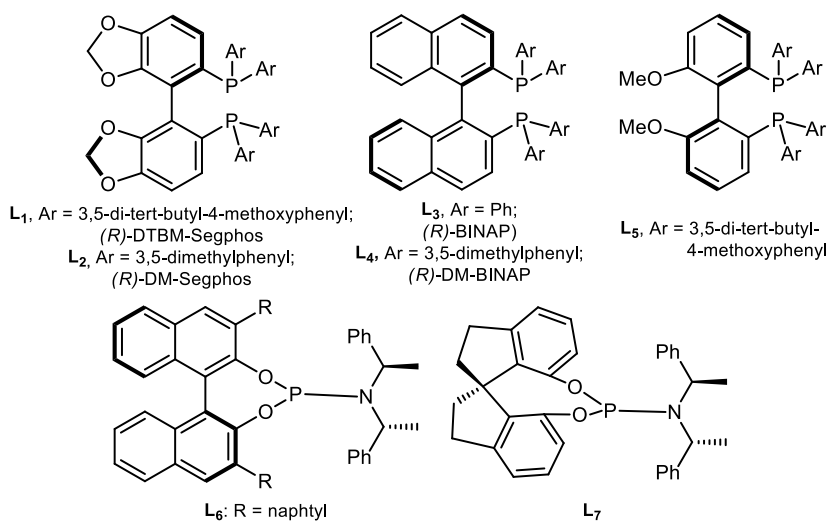


At first, in order to verify the feasibility of our proposal, we performed a preliminary reaction catalyzed by $\mathrm{Au}(\mathrm{JohnPhos})\left(\mathrm{NTf}_{2}\right)$. By conducting the reaction in dichloromethane at $-20^{\circ} \mathrm{C}$, we were pleased to observe the formation of $\mathbf{3 a}$ as single diasteroisomer in $75 \%$ yield (Table 1, entry 1). The structure of 3a, the trans relationship between the substituents on the polycyclic ring and the geometry of the exocyclic double bound were elucidated and demonstrated by mono- and bidimensional NMR analyses and by X-ray (figure 1).

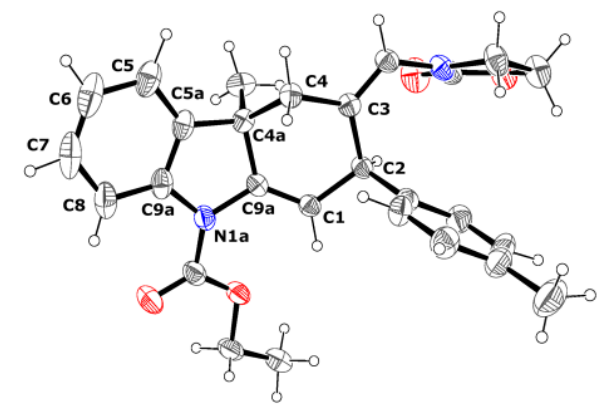

Figure 1. ORTEPIII plot of compound 3a showing the numbering schemes for all non-hydrogen atoms of the tetrahydrocarbazole group. Ellipsoids drawn at $30 \%$ probability.

Then we moved to chiral gold(I) species..$^{\left[{ }^{[g]}\right],[11]}$ In particular, we selected a set of bulky axially chiral biarylphosphine ligands (Table 1, $\mathbf{L}_{\mathbf{1}}-\mathbf{L}_{\mathbf{5}}$ ), characterized by electronic properties closely related to those of JohnPhos ligand. Next, the corresponding dinuclear gold(I) chloride complexes were prepared and used in the screening. ${ }^{[12]}$ In the first enantioselective trial, the use of a chiral cationic catalyst generated in situ from $(R)$-DTBM$\operatorname{SegPhos}\left(\mathbf{L}_{1}\right) \mathrm{Au}_{2} \mathrm{Cl}_{2}$ and $\operatorname{AgNTf}_{2}$ afforded tetrahydrocarbazole $\mathbf{3 a}$ in $72 \%$ yield and with a promising e.r. of 93:7 (Table 1, entry 2). Similarly, other biarylphosphine-based complexes were tested. $(R)$-DM-SegPhos $\left(\mathbf{L}_{2}\right) / \operatorname{gold}(\mathrm{I})$ catalyst was less effective producing 3a in both lower yield and e.r. (Table 1, entry 3). Likewise, BINAP derivatives $\mathbf{L}_{\mathbf{3}}$ and $\mathbf{L}_{4}$ led to worse results with than $(R)$-DTBMSegPhos $\left(\mathbf{L}_{\mathbf{1}}\right)$, affording $\mathbf{3 a}$ in $52 \%$ and $75 \%$ yield, and with e.r. of 63:37 and 80:20, respectively (Table 1, entries 4 and 5). Lastly, cationic gold(I) complex arising from chiral biphenyl ligand $\mathbf{L}_{\mathbf{5}}$ gave the desired product in quite good e.r. $(88: 12)$ but in modest $48 \%$ yield (Table 1, entry 6). For comparison we tested also the activity of chiral monodentate gold(I) phosphoramidites derived from C3,C'3 substitutedBINOL $\left(\mathbf{L}_{6}\right)$ and from spirobiindane $\left(\mathbf{L}_{7}\right)$ ligands. In both cases, despite the good yields, we observed a significant decrease of the e.r. to 46:54 using BINOLderived $\mathbf{L}_{6}$ gold(I) (Table 1, entry 7) and to 67:53 with spirobiindanic $\mathbf{L}_{7}$ gold(I) species (Table 1, entry 8). Having selected $(R)$-DTBM-SegPhos $\left(\mathbf{L}_{1}\right)$ as best chiral ligand, we decided to test the corresponding isolated cationic complex $(R)$-DTBM$\mathrm{SegPhos} \mathrm{Au}_{2}\left(\mathrm{NTf}_{2}\right)_{2}$ in order to avoid any possible interference arising from cationic silver and chloride anion on the reaction outcome. By using the isolated gold complex, the yield of 3a was increased up to $81 \%$ retaining very similar e.r. (Table 1 , entry 9 ). Then, we briefly investigated the role of the temperature on the reaction outcome. Performing the reaction at $-75^{\circ} \mathrm{C}$, we did not observe any substantial difference in terms of e.r., but the cycloaddition proceeded slowly and, after $3.5 \mathrm{~h}, 3 \mathrm{a}$ was isolated in only $18 \%$ yield beside a significant amount of starting vinylindole 1a (Table 1, entry 10). Likewise, when we performed the reaction at $0^{\circ} \mathrm{C}$ we did not observe severe changes in the e.r., however the yield dropped to $61 \%$ because of the formation of some unidentified side-products probably arising from the decomposition of $N$-allenamide $2 \mathbf{a}$ (Table 1, entry 11). Finally, best results were obtained at $-40{ }^{\circ} \mathrm{C}$ and in the presence of a slight excess of allene 2a (Table 1, entry 12). Under these optimized reaction conditions, 3a was prepared in $85 \%$ yield in $3 \mathrm{~h}$ and with an e.r. of 96:4, further increased to 99:1 after one single recrystallization in $\mathrm{CH}_{2} \mathrm{Cl}_{2} / n$-pentane at room temperature.

Based on these results, we next explored the scope of the dearomative [4+2] cycloadditions between 2vinylindoles 1a-h and allenes $\mathbf{2 a - b}$ for the synthesis of tetrahydrocarbazoles $\mathbf{3}$ (Table 2).

By way of comparison, Table 2, entry 1 reports the results for the cycloaddition reaction of $\mathbf{1 a}$ with $\mathbf{2 a}$ under the optimized reaction conditions (Table 1, entry 10). The introduction of an ED group (OMe) on the aryl group at the vinyl moiety (2-vinylindole $1 \mathbf{1 b}$ ) led to $\mathbf{3 b}$ in comparable yield and e.r. (Table 2, entry 2). On the contrary, the presence of a strong inductive EW substituent such as fluorine (2-vinylindole 1c) negatively affected the yield. At $-40{ }^{\circ} \mathrm{C}$, the reaction was proceeding too slowly, therefore, it was necessary to increase the temperature up to $0{ }^{\circ} \mathrm{C}$. After $18 \mathrm{~h}, \mathbf{3 c}$ was isolated in $40 \%$ yield and with e.r. of 91:9 (Table 2 , entry 3 ). This result could be probably due to the adverse influence of the conjugated EW substituent on the residual nucleophilicity of indole's C-3. A similar behavior was also observed when the EW group was located on the indole moiety. Thus, the reaction of 5chloro-substituted 2-vinylindole 1d required higher temperature and afforded $\mathbf{3 d}$ in $61 \%$ yield and e.r. of 90:10 (Table 2, entry 4). Furthermore, the presence of an alkyl substituent at the vinyl moiety (vinylindole 1e) was tolerated, even if both yield and enantioselectivity of the reaction were considerably decreased (Table 2, entry 5). We evaluated also the influence of the substituent on the C-3 of indole. Apart from methyl group, the reaction proceeded well also with the unsubstituted 2-vinylindole 1f, and with the 3-ethyl derivative $\mathbf{1 g}$ leading to carbazoles $\mathbf{3 f}$ and $\mathbf{3 g}$ in good yield and e.r. (table 2, entries 6 and 7). However, the reaction did not tolerate the presence of a C-3 phenyl ring (vinylindoles $\mathbf{1 h}$ ), and any product could be isolated (Table 2 , entry 8 ). 
Table 2. Scope of the reaction between 2 -vinylindoles $\mathbf{1}$ and allenamides $\mathbf{2}$ under gold(I) catalysis. ${ }^{\text {[a] }}$

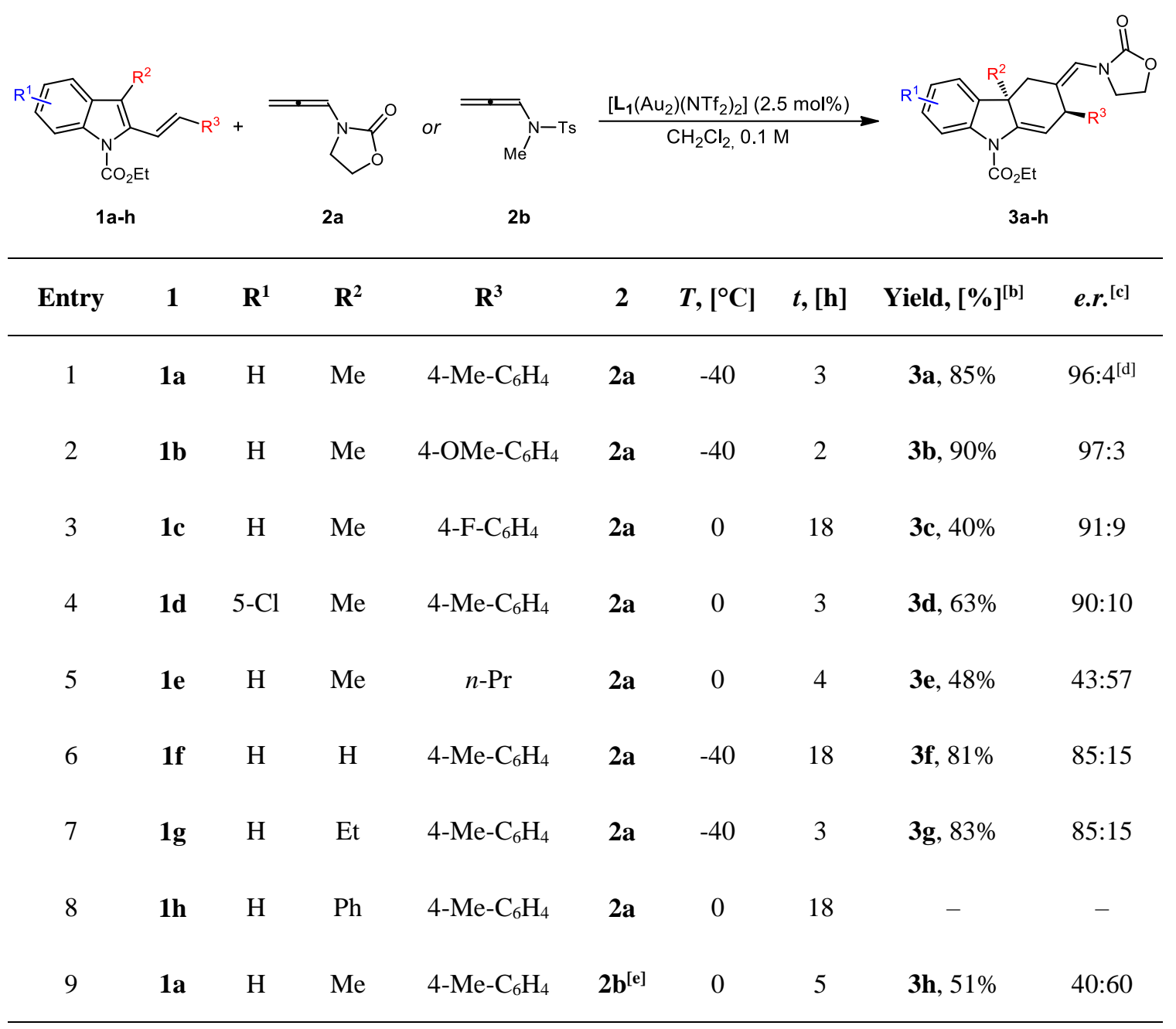

[a] Reaction conditions: 1 ( $0.2 \mathrm{mmol}), \mathrm{N}$-allenammide $\mathbf{2 a}$ (1.2 equiv.), chiral gold(I) catalyst $(2.5 \mathrm{~mol} \%)$, in $\mathrm{CH}_{2} \mathrm{Cl}_{2}$ $(0.1 \mathrm{M})$. [b] Isolated yield. [c] Determined by HPLC on pure isolated product. [d] Increased to 99:1 after one single recrystallization. [e] $\mathbf{2 b}$ (3 equiv.) added with syringe pump during $3 \mathrm{~h}$, final concentration $=0.05 \mathrm{M}$.

Finally, we changed the nature of the $N$-allenamide, by testing the reactivity of $N$-tosyl derivative $\mathbf{2} \mathbf{b}$. The corresponding product $\mathbf{3 h}$ was isolated in moderate yield $(51 \%)$ and poor e.r. of 40:60 (Table 2, entry 9). In addition, this latter reaction was performed under carefully biased reaction conditions with the aim to minimize the dimerization of allenamide 2b. ${ }^{[13]}$ Considering the good results obtained with 3substitued-2-vinylindoles $\mathbf{1}$, we decided to briefly evaluate a possible extension of the scope to isomeric 2-methyl-3-vinylindoles $\mathbf{4}$ and allenamide $\mathbf{2 a}$ (Table 3).

The reaction performed under the optimized conditions with 2-methyl-3-vinylindole $\mathbf{4 a}$ and allenamide $\mathbf{2 a}$ gave the corresponding isomeric dearomatized tetrahydrocarbazoles $\mathbf{5} \mathbf{a}$ and $\mathbf{5}$ ' $\mathbf{a}$ in $84 \%$ overall yield in 2.2/1 mixture (Table 3, entry 1). Isomeric 5a and 5'a were easily separated by flash chromatography and chiral HPLC analysis revealed that they were formed in high $e . r$. . The geometry of the exocyclic double bond was determined via mono and bidimensional NMR analysis (see supporting information). Similarly, 3-vinylindole $\mathbf{4 b}$, bearing an ED ethoxy group on the aryl at the vinyl moiety, afforded $\mathbf{5} \mathbf{b}$ and $\mathbf{5}$ 'b with high overall yield and e.r. (Table 3, entry 2). On the contrary, as observed for 3methyl-2-vinylindoles $\mathbf{1}$, the introduction of EW group at the same position of derivatives 4 affected the reactivity. For example, the reaction of 2-methyl-3-(4fluorostyryl)indole $\mathbf{4 c}$, gave high yield of the corresponding tricyclic derivative $\mathbf{5 c}(85 \%$, e.r. $88: 12)$ only when the temperature was raised to $0{ }^{\circ} \mathrm{C}$ (Table 3 , entry 3). On the other hand, an ED group on indole moiety is well tolerated and $\mathbf{4 d}$ afforded the corresponding products $\mathbf{5 d}$ and 5'd with high overall yield and e.r. for both carbazoles (Table 3, entry 4). 
Table 3. Scope of the reaction between 3-vinylindoles $\mathbf{4}$ and allenamide $\mathbf{2 a}$ under gold(I) catalysis. ${ }^{\text {[a] }}$

\begin{tabular}{|c|c|c|c|c|c|c|c|c|}
\hline & & \multicolumn{2}{|c|}{$2 a$} & \multicolumn{3}{|r|}{$5 a-d$} & \multicolumn{2}{|c|}{ 5'a-c } \\
\hline Entry & 4 & $\mathbf{R}^{1}$ & $\mathbf{R}^{2}$ & $\mathrm{~T},\left[{ }^{\circ} \mathrm{C}\right]$ & $t,[\mathrm{~h}]$ & $\begin{array}{c}\text { Overall yield, } \\
{[\%]^{[b]}}\end{array}$ & $5 / 5$ & $e . r^{[c]}$ \\
\hline 1 & $\mathbf{4 a}$ & $\mathrm{H}$ & $4-\mathrm{Me}-\mathrm{C}_{6} \mathrm{H}_{4}$ & -40 & 1.5 & $97 \%$ & $2.2 / 1$ & $\begin{array}{c}\text { 5a: } 92: 8 \\
\text { 5'a: } 96: 4\end{array}$ \\
\hline 2 & $4 b$ & $\mathrm{H}$ & 4-OEt- $\mathrm{C}_{6} \mathrm{H}_{4}$ & -40 & 1.5 & $80 \%$ & $1 / 2.2$ & $\begin{array}{l}\mathbf{5 b}: 92: 8 \\
\mathbf{5} \mathbf{b}: 99: 1\end{array}$ \\
\hline 3 & $4 c$ & $\mathrm{H}$ & $4-\mathrm{F}-\mathrm{C}_{6} \mathrm{H}_{4}$ & 0 & 3 & $85 \%$ & $>20: 1$ & 5c: $88: 12$ \\
\hline 4 & 4d & $\mathrm{Me}$ & $4-\mathrm{Me}-\mathrm{C}_{6} \mathrm{H}_{4}$ & -40 & 2 & $85 \%$ & $1 / 1.6$ & $\begin{array}{c}\text { 5d: } 92: 8 \\
\text { 5'd: } 98: 2\end{array}$ \\
\hline
\end{tabular}

[a] Reaction conditions: 1 (0.2 mmol), $N$-allenammide 2a (1.2 equiv.), chiral gold(I) catalyst (2.5 mol\%), in $\mathrm{CH}_{2} \mathrm{Cl}_{2}(0.1 \mathrm{M})$. [b] Isolated yield. [c] Determined by HPLC on pure isolated product.

In accordance with our previous reports ${ }^{[10 a, c]}$ and with the results obtained by Zhang, Xia and coworkers ${ }^{[10 \mathrm{~b}]}$ in the cycloadditions of 3-unsubstituted-2vinylindoles and 2-unsubstituted-3-vinylindoles, the mechanisms we proposed for the reaction of $\mathbf{1 a}$ and $\mathbf{4 a}$ with $\mathbf{2 a}$ are very close as illustrated in Scheme 3.

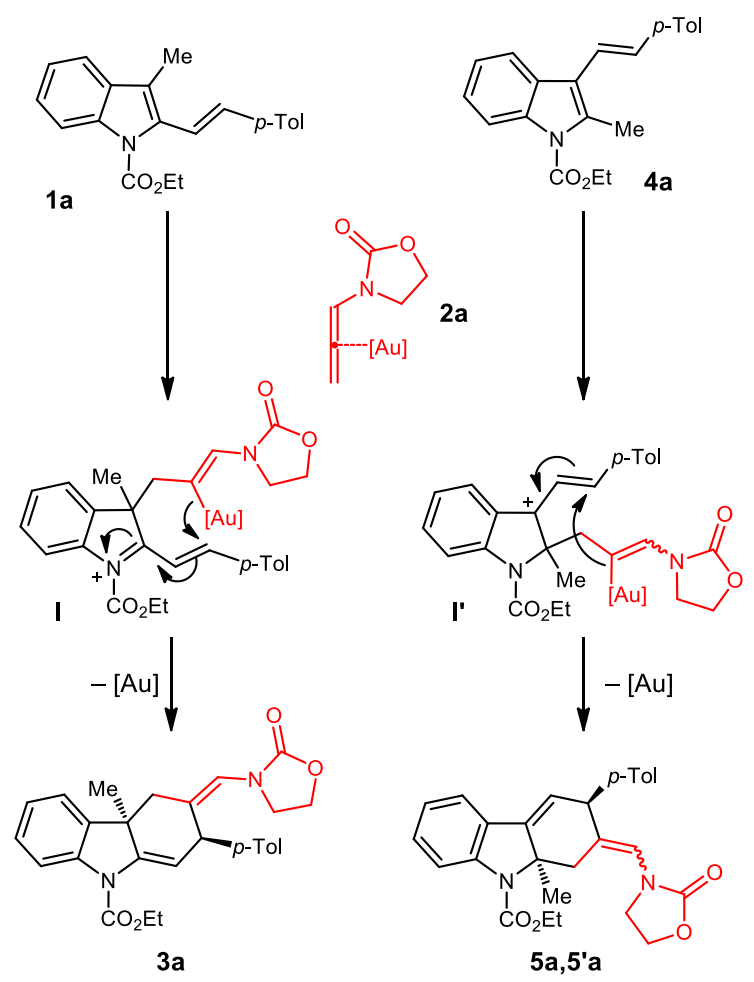

Scheme 3. Proposed reaction mechanism for the [4+2] cycloadditions.
Thus, the reactions proceed via a stepwise mechanism initially with the formation of a new bond between $\mathrm{C} 2$ or $\mathrm{C} 3$ of indole and the external allene carbon atom affording the dearomatized cationic intermediates $\mathbf{I} / \mathbf{I}$, respectively. The regiochemistry of the addition is dictated in both cases by the presence of an EW group at nitrogen and of the ED methyl group in position 2 or 3 on the indole nucleus. ${ }^{[10 \mathrm{a}-\mathrm{c}, 9 \mathrm{e}]}$ The reactions then proceed with the formation of a second carbon-carbon bond restoring the catalyst and resulting in formal [4+2] cycloaddition products $\mathbf{3 a}$ and $\mathbf{5 a / 5}$ 'a. The stereochemistry around the external double bond in the final products is determined by steric factors. Thus, when the steric hindrance around the double bond in the first intermediate is small the reactions resulted in the isolation of both $(Z)$ and $(E)$ isomers. ${ }^{[10 b]}$

Theoretically, the use of these 2,3-disubstituted indoles as dienes would have made the [4+2] cycloaddition more challenging because of plausible regioselection issues in the formation of the proper intermediates. In fact, since these reactions proceed via a stepwise mechanism, ${ }^{[10]}$ the formation of the key reaction intermediates $\mathbf{I} / \mathbf{I}$ ' depends on the selective nucleophilic attack of indole $\mathrm{C} 3$ or $\mathrm{C} 2$ on allenamide and is essential for the further cyclization step leading to the final reaction products. However, products arising from a complementary regiochemical path has been never observed or detected.

\section{Conclusion}

In conclusion, we reported an asymmetric gold(I) catalyzed $[4+2]$ cycloaddition of 3 -substituted 2vinylindoles and 2-methyl-3-vinylindoles with $\mathrm{N}$ allenamides. In most cases, the reactions proceeded 
with satisfactory yields and with good to excellent $e . r$. Thus, we introduced the first dearomative [4+2] cycloaddition of 2,3-disubstituted-vinylindoles with simple $\pi$-systems as dienophiles for the easy construction of chiral carbazole derivatives bearing a quaternary stereogenic center at $\mathrm{C} 4 \mathrm{a}$ (compounds $\mathbf{3}$ ) or at C9a (compounds 5, 5'). This study well complements previous studies on the enantioselective dearomative [4+2] cycloaddition of 3-substituted-2vinylindoles with classical activated dienophiles ${ }^{[13]}$ and related studies in the field of gold-mediated [4+2] cycloaddition reactions of vinylindoles with allenes. ${ }^{[10]}$

\section{Experimental Section}

\section{Typical procedure for the synthesis of tetrahydrocarbazoles 3}

To a solution of $\left[(R)\right.$-DTBM-SegPhos $\left.\mathrm{Au}_{2}\left(\mathrm{NTf}_{2}\right)_{2}\right](0.005$ mmol, $2.5 \mathrm{~mol} \%)$ in $\mathrm{CH}_{2} \mathrm{Cl}_{2}(1.0 \mathrm{ml}), 3$-substitued-2vinylindole 1a-h $(0.2 \mathrm{mmol}, 1.0$ equiv.) was added and the mixture was cooled to -40 or $0{ }^{\circ} \mathrm{C}$. Then, a solution of $\mathrm{N}$ allenamide 2a-b $(0.22 \mathrm{mmol}, 1.2$ equiv. $)$ in $\mathrm{CH}_{2} \mathrm{Cl}_{2}(1.0 \mathrm{ml}$, final concentration ca. $0.1 \mathrm{M}$ ) was added dropwise and the reaction was stirred at the same temperature until disappearance of the starting materials (checked by TLC, see Table 2). The reaction was quenched with $\mathrm{PPh}_{3}(0.03$ mmol, $15 \mathrm{~mol} \%$ ) and the solvent was removed under vacuum. Purification by column chromatography yielded the corresponding tetrahydrocarbazoles $\mathbf{3 a}-\mathbf{h}$.

\section{Supporting Information Available}

Detailed descriptions of experimental procedures and the spectroscopic data of the products as well as the crystal structures are presented in the Supporting Information. CCDC 1536255 (3a) contains the supplementary crystallographic data for this paper. These data can be obtained free of charge from The Cambridge Crystallographic Data Centre via www.ccdc.cam.ac.uk/data_request/cif.

\section{Acknowledgements}

We thank MIUR-Italy (post-doctoral fellowship to V.P.) for financial support. D. Nava and G. Celentano are acknowledged for NMR, mass and HPLC analyses.

\section{References}

[1] a) A. W. Schmidt, K. R. Reddy, H.-J. Knölker, Chem. Rev. 2012, 112, 3193-3328; b) A. Głuszyńska, Eur. J. Med. Chem. 2015, 94, 405-426; c) L. S. Tsutsumi, D. Gundisch, D. Sun, Curr. Top. Med. Chem. 2016, 16, 1290-1313.

[2] a) U. Pindur, Heterocycles 1988, 27, 1253-1268; b) U. Pindur, Adv. Nitrogen Heterocycl. 1995, 1, 121-172; c) R. F. Kester, S. J. Berthel, F. Firooznia, Top. Heterocycl. Chem. 2010, 26, 327396.

[3] For selected recent examples of regio- and diastereoselective reactions see: a) G. Abbiati, V. Canevari, D. Facoetti, E. Rossi, Eur. J. Org. Chem. 2007, 517-525; b) V. Pirovano, G. Abbiati, M. Dell'Acqua, D. Facoetti, M. Giordano, E. Rossi, Synlett 2012, 23, 2913-2918; c) V. Pirovano, M. Dell'Acqua, D. Facoetti, S. Rizzato, G. Abbiati, E. Rossi, Eur. J. Org. Chem.
2013, 6267-6279; d) K. Ozaki, H. Zhang, H. Ito, A. Lei, K. Itami, Chem. Sci. 2013, 4, 3416-3420; e) J. Cowell, M. Abualnaja, S. Morton, R. Linder, F. Buckingham, P. G. Waddell, M. R. Probert, M. J. Hall, RSC Adv. 2015, 5, 1612516152; f) E. Rossi, V. Pirovano, M. Negrato, G. Abbiati, M. Dell'Acqua, Beilstein J. Org. Chem. 2015, 11, 1997-2006; g) N. H. Krishna, A. P. Saraswati, M. Sathish, N. Shankaraiaha, A. Kamal, Chem. Commun. 2016, 52, 4581-4584.

[4] For selected recent examples of regio- and diastereoselective reactions see: a) C.-B. Chen, X.-F. Wang, Y.-J. Cao, H.-G. Cheng, W.-J. Xiao, J. Org. Chem. 2009, 74, 3532-3535; b) F. Tan, F. Li, X.-X. Zhang, X.-F. Wang, H.-G. Cheng, J.-R. Chen, W.-J. Xiao, Tetrahedron 2011, 67, 446-451.

[5] a) C. Gioia, A. Hauville, L. Bernardi, F. Fini, A. Ricci, Angew. Chem. Int. Ed. 2008, 47, 9236-9239; b) C. Gioia, L. Bernardi, A. Ricci, Synthesis 2010, 161-170; c) X.-F. Wang, J.-R. Chen, Y.-J. Cao, H.-G. Cheng, W.-J. Xiao, Org. Lett. 2010, 12, 11401143.

[6] X. Tian, N. Hofmann, P. Melchiorre, Angew. Chem. Int. Ed. 2014, 53, 2997-3000.

[7] a) C. Zheng, Y. Lu, J. Zhang, X. Chen, Z. Chai, W. Ma, G. Zhao, Chem. Eur. J. 2010, 16, 5853-5857; b) Y.-J. Cao, H.-G. Cheng, L.-Q. Lu, J.-J. Zhang, Y. Cheng, J.-R. Chen, W.-J. Xiao, Adv. Synth. Catal. 2011, 353, 617-623; c) J.-W. Ren, Z.-F. Zhou, J.-A. Xiao, X.-Q. Chen, H. Yang, Eur. J. Org. Chem. 2016, 1264-1268; d) D. Enders, C. Joie, K. Deckers, Chem. Eur. J. 2013, 19, 10818-10821.

[8] a) F. Tan, H.-G. Cheng, W. Wu, K.-R. Ding, W.-J. Xiao, Chem. Asian J. 2012, 7, 493-497; b) B. Ouyang, T. Yu, R. Luoa, G. Lu, Org. Biomol. Chem. 2014, 12, 4172-4176; c) S. Harada, T. Morikawa, A. Nishida, Org. Lett. 2013, 15, 5314-5317; d) Y. Huang, L. Song, L. Gong, E. Meggers, Chem. Asian J. 2015, 10, 2738-2743.

[9] Reviews on gold-catalyzed cycloadditions of allenes: a) Y. Li, W. Li, J. Zhang, Chem. Eur. J. 2017, 23, 467-512; b) E. Manoni, A. De Nisi, M. Bandini, Pure Appl. Chem. 2016, 88 , 207-214; c) F. López, J. L. Mascareñas, Chem. Soc. Rev. 2014, 43, 2904-2915; d) M. E. Muratore, A. Homs, C. Obradors, A. M. Echavarren, Chem. Asian J. 2014, 9, 3066-3082; e) W. Yang, A. S. K. Hashmi, Chem. Soc. Rev. 2014, 43, 2941-2955; f) S. Montserrat, H. Faustino, A. Lledos, J. L. Mascareñas, F. López, G. Ujaque, Chem. Eur. J. 2013, 19, 15248-15260; g) F. López, J. L. Mascareñas, Beilstein J. Org. Chem. 2013, 9, 2250-2264; h) F. López, J. L. Mascareñas, Beilstein J. Org. Chem. 2013, 9, 2250-2264; i) F. López, J. L. Mascareñas, Beilstein J. Org. Chem. 2011, 7, 1075-1094; 1) S. Montserrat, G. Ujaque, F. López, J. L. Mascareñas, A. Lledos, Top. Curr. Chem. 2011, 302, 225-248. Specific examples of intermolecular gold-catalyzed [4+2] cycloadditions of allenes: m) G. Wang, Y. Zou, Z. Li, Q. Wang, A. Goeke, Adv. Synth. Catal. 2011, 353, 550-556; n) H. Faustino, F. López, L. Castedo, J. L. Mascareñas, Chem. Sci. 2011, 2, 633-637; o) J. Francos, F. Grande-Carmona, H. Faustino, J. IglesiasSigüenza, E. Díez, I. Alonso, R. Fernández, J. M. Lassaletta, F. López, J. L. Mascareñas, J. Am. Chem. Soc. 2012, 134, 1432214325.

[10] a) V. Pirovano, L. Decataldo, E. Rossi, R. Vicente, Chem. Commun. 2013, 49, 3594-3596; b) Y. Wang, P. Zhang, Y. Liu, F. Xia, J. Zhang, Chem. Sci., 2015, 6, 5564-5570; c) V. 
Pirovano, E. Arpini, M. Dell'Acqua, R. Vicente, G. Abbiati, E. Rossi, Adv. Synth. Catal. 2016, 358, 403-409.

[11] For selected reviews on asymmetric gold catalysis, see: a) Angew. Chem. Int. Ed. 2008, 47, 2178-2181; b) R. A. Widenhoefer, Chem. Eur. J. 2008, 14, 5382-5391; c) A. Pradal, P. Y. Toullec, V. Michelet, Synthesis 2011, 10, 1501-1514; d) G. Cera, M. Bandini, Isr. J. Chem. 2013, 53, 848-855; e) Y. M. Wang, A. D. Lackner, F. D. Toste, Acc. Chem. Res. 2014, 47, 889-901.

[12] For the preparation of gold(I) complexes see: a) N. Mézailles, L. Ricard, F. Gagosz, Org. Lett. 2005, 7, 4133-4136; b) M. J. Johansson, D. J. Gorin, S. T. Staben, F. D. Toste, J. Am. Chem. Soc. 2005, 127, 18002-18003; c) L. Ricard, F. Gagosz, Organometallics 2007, 26, 4704-4707.
[13] For selected examples on gold-catalyzed dimerization of $N$ allenamides see: a) X.-X. Li, L.-L. Zhu, W. Zhou, Z. Chen, Org. Lett. 2012, 14, 436-439; b) S. Suárez-Pantiga, C. Hernández-Diáz, E. Rubio, J. M. González, Angew. Chem., Int. Ed. 2012, 51, 11552-11555.

[14] a) S. B. Jones, B. Simmons, D. W. C. MacMillan, J. Am. Chem. Soc. 2009, 131, 13606-13607; b) S. B. Jones, B. Simmons, A. Mastracchio, D. W. C. MacMillan, Nature 2011, 475, 183-188; c) B. D. Horning, D. W. C. MacMillan, J. Am. Chem. Soc. 2013, 135, 6442-6445; d) B. N. Laforteza, M. Pickworth, D. W. C. MacMillan, Angew. Chem. Int. Ed. 2013, 52, 11269-11272.

This document is the Accepted Manuscript version of a Published Work that appeared in final form in "Advanced Synthesis \& Catalysis", copyright (C) Wiley-VCH, after peer review and technical editing by the publisher. To access the final edited and published work see http://dx.doi.org/10.1002/adsc.2017002 